\title{
Public engagement and the influence imperative
}

\author{
PHILIP N. COHEN \\ University of Maryland
}

April 7, 2018

This is an invited essay for Contemporary Sociology.

\begin{abstract}
A review essay discussing three advice books for social scientists. Sociologists, in responding to the imperative to make their work more influential, must go beyond doing "public sociology” to embrace doing sociology "in public" (Healy 2017). Rather than using public engagement primarily for publicity - to make our research matter - we should use engagement to help us do research that matters in the first place. Next, I caution that the drive to be professionally rewarded for public intellectualism is fraught with conflicts that may be irreconcilable. To be a public intellectual today requires being both public in one's intellectual life and intellectual in one's public life, and for academics in the era of the "market university" (Berman 2011), trying to get paid for that leads to a neoliberal trap. Finally, I argue for a move beyond personal strategies toward the development of the open scholarship as an institutional response that ultimately may be responsible for sociology’s survival.
\end{abstract}




\title{
Public engagement and the influence imperative
}

\author{
PHILIP N. COHEN \\ University of Maryland
}

Going Public: A Guide for Social Scientists, by Arlene Stein and Jessie Daniels. Chicago: University of Chicago Press, 2017. 224 pp. \$19 paper. ISBN14: 9780226364780.

The Social Scientist's Soapbox: Adventures in Writing Public Sociology, by Karen Sternheimer. London: Routledge, 2018. 102 pp. \$24 paper. ISBN14: 9781138056435.

The Public Professor: How to Use Your Research to Change the World, by M. V. Lee Badgett. New York: NYU Press, 2016. 256 pp. \$24 paper. ISBN14: 9781479861392.

These three books, by three sociologists (Stein, Daniels, and Sternheimer) and an economist (Badgett), address the demand for guidance and support as academic sociologists respond to the disciplinary imperative to make our work more influential. This imperative is largely internal, reflecting the ambitions of sociologists ourselves, who are frustrated by the success of others (hello, economics) in influencing public policy. It is perennial, but also a response to contemporary external threats, including higher education budget squeezes, falling college enrollment shares, and of course the current national political cataclysm. Make of this fact what you will: All three books feature bullhorns on their covers.

Each book addresses the rationale for going public in your sociology and also offers advice for how to do it. Lee Badgett is most focused on policy work, asking, "How do we get policymakers, the media, and community members to pay attention to us?” (p. 7). Karen Sternheimer directs most of her advice toward writing; she asks, "How do you make your research appealing to others?” (p. 6) And Arlene Stein and Jessie Daniels, who take an activist focus, are more imperative: “There's a big world out there that needs to hear from us” (p. 5).

Together, these books add to what Douglass Hartmann (2017:4) has called "a new, golden age of sociological engagement, visibility, and influence.” And yet sociologists confront ambiguous institutional signals. If this a golden age for sociological engagement, it's one in which the discipline finds itself oddly uncentered. Public engagement is not part of our core training; most sociology programs don't teach writing for non-academic audiences, nor do they offer instruction in the structures or workings of the scholarly communication system, the information economy, the news media, or social media.

By my count, among the four most popular sociologists on Twitter - those with more than 100,000 followers - two (Michael Eric Dyson and Zeynep Tufekci) do not have sociology PhDs, one (Conrad Hackett) works at the Pew Research Center, and one (Eve Ewing) is an assistant professor in social service administration. The sociology books that are most read outside academia are by ethnographers, a group with a less-than-dominant position in the discipline. 
Despite being the announced goal of a slew of our association's elected presidents, can we say public engagement is a core ambition of our discipline? The authorities we answer to are unsure how (or whether) to reward (or punish) sociologists who bring attention to their institutions by joining the public fray, and we have no consensus on shared goals regarding such efforts. (In my own department, as in most others, promotion based on "research, teaching, and service" does not include writing outside of academia, appearing on TV, or having a lot of followers on Twitter.) And what is our claim to institutional rewards for this work? Maybe we should be rewarded for serving the public good by sharing our research more widely. But does it serve the public good if we at the same time use our platforms to express our own (minority) political views? Maybe we should be rewarded for bringing positive attention to our institutions, to help them enhance their public image. But does that require (or merely encourage) milquetoast engagement limited to, say, extolling the tolerance of diversity? As we extend our reach outside the walls of the "market university" (Berman 2011), who is the customer, and what - or who - is the product?

These books are, quite reasonably, more concerned with giving actionable advice than with thoroughly addressing such questions, although it speaks well of them that they inspire the discussion. Unfortunately, it's hard to publish a print book of advice on these topics in which most material is practically useful to a wide swath of academics, who come at the topic from different perspectives and kinds of experience. Each has good advice and tells good stories, as well as passages that are clunky or already dated. Together, however, they have a wealth of food for thought. The authors all have valuable experience on which to base their advice, and each draws on the knowledge they have gained to help make their book engaging. Badgett has been a leader in LGBT policy and related issues, including testifying before Congress and appearing as an expert witness. Sternheimer has written a number of books about popular culture, and edits the Everyday Sociology blog; Daniels is the co-editor of the Racism Review website and writes prolifically about racism and digital technologies; and Stein was an editor of Contexts and has written several trade books.

\section{More than an audience}

Digital technology- and especially social media - have provided us with useful tools to facilitate the work we already do. But they also have fundamentally altered our position as scholars vis-à-vis the public. As Kieran Healy (2017:771) observed when he summed up the period since Michael Burowoy’s 2004 call to public sociology: “one of social media’s effects on social science has been to move us from a world where some people are trying to do 'public sociology' to one where we are all, increasingly, doing 'sociology in public.”' Those who successfully adapt to this environment must learn to move beyond a workflow in which there is “a research phase and a publicity phase” (Healy 2017: 775).

This fundamental transition affects sociologists whether we like it or not. The public is already here. Before we "publish" our work, they read the abstracts of our grants, critique our syllabi and curriculum requirements, and peruse our conference programs. Given the 
opportunity, they will also read our working papers, borrow our code, and offer their observations about our subjects of study. So the imperative is not just to reach the public with our research, but to learn to work in public as we do our research. Although such an adjustment is complicated and there are obvious pitfalls - as we attempt to operate simultaneously in fields of interaction that are governed by different rules and reward systems - the potential benefits are great. And the alternative is bleak. If sociologists' work is interesting or important, it will be seen, scrutinized, and criticized in public, and we will be held multiple standards. "The only sure way for scholars to escape any and all controversy,” write Stein and Daniels, "is by doing unremarkable work that contributes little of broad interest, or work that is so inconsequential—or impenetrable - that it's incapable of ruffling anyone's feathers because so few people care about it, or understand it” (p. 154).

Too often, however, this public interaction is seen as unidirectional, with the sociologist attempting to use online communications as a more efficient broadcast technology - a bullhorn, if you will. Thus, in Sternheimer's model, research and writing generally precede public engagement, the goal of which is "aiming" your writing to reach a "target audience" (p. 32). Of course you want your writing to speak to the audience for which it's intended, and Sternheimer's guidance on this is valuable, but the direction of communication is almost all outward. She offers a definition of "intellectual" as someone who "can explain interesting and important ideas in an engaging manner" (p. 45), but public intellectuals also must learn from different people with diverse kinds of knowledge. Technological advance has made it more efficient to "get your ideas out there” (p. 58), but it has also multiplied our capacities to get other people's ideas in here, and that's not an opportunity we can afford to forego.

Sternheimer, who doesn't use Twitter, describes the benefits of developing research ideas with a "supportive friend” or "someone who isn’t an expert” as a "brainstorming partner” (p. 30). Then, in the writing process, "One way to figure out if you have a good hook is to use it in conversation and see how people respond" (p. 43). This is sound advice, but better still to use social media to enhance not only the speed of such interactions, but their social reach as well, allowing you to develop ideas and test writing hooks with people you don't routinely engage. This won't work if you take the advice she offers about Twitter, which is defensive: "Don't share even kernels of ideas that are not fully formed if you are not ready to elaborate on them” (p. 58). That advice is misguided. Learning to process in public is extremely valuable, including the opportunity to be wrong, learn, and improve in dialogue with the publics of which we should consider ourselves part. (It is telling that the advice about Twitter is in a chapter titled "Promoting your work to the public.")

Badgett also centers the goal of getting your ideas out there, but she better recognizes the value of interaction. "People who use [social media] only for self-promotion," she writes, "are missing the boat" (p. 146). Once you have scanned the policy environment (and here her advice is excellent) the interactions with different communities and their leaders "might lead you to new research on emerging questions ... and might even involve identifying new research projects that you would take on to address the gaps you've identified" (38). This is essential. The goal of 
public engagement should not be just to make your research matter, but also to do research that matters in the first place.

I should add that “engagement” doesn't have to be direct. We engage with people by reading their published work as well. Thus, this advice from Stein and Daniels, about writing a popular book, is undoubtedly correct: "If you believe that your research would be of interest to a general reader, we suggest that you read some best-selling works of serious nonfiction” (76). But we can make it stronger: If you do not read some best-selling works of serious nonfiction, you are not going to write a best-selling work of serious nonfiction. Similarly, if the following advice is necessary for sociologists who want to write for popular audiences, we're in worse shape than I thought: "If ... your goal is to reach the audience of regular readers of the New York Times, you might start paying attention to what's in the news” (124).

\section{About your career}

If you write in American Sociological Review, should the New York Times publish your op-ed? If the Times publishes your op-ed, should your university give you tenure? In other words, what is the exchange rate between the forms of capital accumulated in these different fields, the "public" and the "academic"? In Bourdeiu's (1998) terms, to have influence in a field, you have to be in its game, which means having a relation of illusio to that field. If you want to win acclaim in public, and you demand that the market university include your public work in its counting of beans, then you subject yourself to the mode of evaluation, the values, and the imperatives of both fields. To be successful in both fields for doing the same work may not be possible without fatally compromising its meaning (which doesn't mean it's not done; it is, by those academics who successfully display disinterestedness in both arenas, who mostly seem to be economists with noncontroversial views).

To be a public intellectual today requires being both public in one's intellectual life and intellectual in one's public life. Being public in our academic work is essential for accountability, and is increasingly recognized as a prerequisite for scientific integrity; that's a professional responsibility. On the other hand, having a public life means participating in civil society, building a network of interaction in the public sphere, and committing ourselves to the public good; that's a civic responsibility. Some people are lucky enough to get paid for doing both, but to insist that we do, to make civic intervention definitional to our professional work, leads to a neoliberal trap. And it risks corruption by the impurities of economic interest, which may be inimical to the values we bring to either or both fields.

What I'm trying to say is, making politics or activism part of our sociologist job description is often a bad idea, but that doesn't mean we shouldn't operate in both fields. We should use facts in our public speech, and passion in our sociological research. The best ethnographies surely capture the public imagination because their authors use language that is approachable and they illuminate the humanity of their subjects. But it's probably also because they develop and communicate their own passions as well, which is part of what makes them the best ethnographies. My suggestion is to be a good citizen because it's the right thing to do, and 
use your intellectual abilities to do that because that's part of what you have to offer. In the process, your research will probably get better, too. I know this is not very concrete advice.

Embracing the movement between public and academic spheres is "translating" in the dynamic sense of that word. Stein and Daniels model this with the story of a paper by Daniels (2013) about racism and Internet studies that grew from a tweet at a conference, to a blog post series, to a peer-reviewed paper. That inspired me to tell the story of a paper I published - on recession and divorce - which began with a critical blog post in 2009, followed by twitter exchanges, colloquium presentations, media coverage, and sharing research materials, before finally being published in 2014 in a form that reflected the whole chain of engagement (Cohen 2018). Experiences like these show the advantage of developing feedback between public and academic parties. Similarly, Badgett includes examples of engaged policy work that brought shared benefits to scholars and policy stakeholders.

\section{Open scholarship}

Despite some welcome honorable mentions, none of these books adequately acknowledges the central importance of open scholarship as a structural response to the influence imperative that our discipline faces - which is not surprising given the lack of recognition this issue has received in our discipline to date, especially from the American Sociological Association. We can do better. This belongs high on the agenda of both personal career advice and institutional reform to improve the status and efficacy of sociology as a discipline. Open scholarship includes not just open access dissemination of research findings, but also sharing data, code, and other materials from the research lifecycle. Our attempts to engage with the public, in the full sense of both terms, will be sustained by a research environment in which "the process, content, and outcomes of research are openly accessible by default” (Nosek 2017). (Nosek's Center for Open Science is a major initiative in this direction; it also hosts SocArXiv, an open archive for the social sciences, of which I am director.)

This is a visionary vision, but also a practical perspective, and a reasonable response to the reality of doing social science in public. The publics with which we seek to engage include not only audiences to whom we speak, but also politicians who fund us, policy activists who use our results, researchers in other fields, journalists who do their own data analysis, librarians who curate and disseminate our work, and citizen scientists who both critique and collaborate with us. The goals of legitimacy, efficiency, and efficacy are all served by our openness. In order to make public engagement more than a shallow exercise in broadcasting or marketing our results, sociologists have to make ourselves more vulnerable where it counts. Making public statements, with the risks that entails, is important. But to earn the trust of our publics, and gain the full benefit of their support, we must also be willing to take the greater risk of pulling back the curtain on our research. This is increasingly recognized by the institutions that fund us, and we would do well to get out from behind on this crucial aspect of the imperative.

I hope that one outcome of these books, and the drive to engagement they embolden, is to encourage more sociologists to pursue public pathways through their careers. The more people 
make that effort, the more we will accumulate the evidence and experience necessary to move beyond personal strategies and develop the institutional responses that ultimately may be responsible for sociology’s survival.

\section{References}

Berman, Elizabeth Popp. 2011. Creating the Market University: How Academic Science Became an Economic Engine. Princeton University Press.

Bourdieu, Pierre. 1998. Practical Reason: On the Theory of Action. Stanford University Press.

Cohen, Philip N. 2018. "How I engaged my way to excellent research success and you can too.” Family Inequality, April 1. https://familyinequality.wordpress.com/2018/04/01/how-i-engagedmy-way-to-excellent-research-success-and-you-can-too/.

Daniels, Jessie. 2013. “Race and Racism in Internet Studies: A Review and Critique.” New Media \& Society 15 (5): 695-719.

Hartmann, Douglas. 2017. "Sociology and Its Publics: Reframing Engagement and Revitalizing the Field.” Sociological Quarterly 58 (1): 3-18.

Healy, Kieran. 2017. "Public Sociology in the Age of Social Media.” Perspectives on Politics 15 (3): 771-80.

Nosek, Brian A., 2017. “Center for Open Science: Strategic Plan.” Open Science Framework. March 6. doi:10.17605/osf.io/x2w9h. 